And réia Cristina Lopes Frazão da Silva

Universida de Federal do Rio de Janeiro

\title{
O corpo e a came: uma leitura das obras Vida de Santo Domingo de Silos e Vida de Santa Oria a partir da categoria gênero
}

\begin{abstract}
Resumo: Baseado na proposição do pós-estruturalismo, adotada por J oan Scott, de que "os signific adosnã o são fixos no léxic o de uma cultura", o presente artig o tem como objetivo discutir, usando a categoria de gênero, os significa dos de duas palavras espa nholas medievais - cuemo e came - em textos hagiográficos que foram escritos por Gonzalo de Berceo na primeira a meta de do século XIII, Vida de Santo Domingo de Silos e Vida de Santa Oria. Queremos verificar, procurando ambigüidades e conflitos, como a categoria gênero é articulada às concepções de Berceo sobre o corpo e a carne.

Palavras-chave: Idade Média; gênero; hagiografia; corpo; carne.
\end{abstract}

Copyright $\propto 2006$ by Revista Estud os Feministas.

${ }^{1}$ BÍBபA DEJ ERUSALÉM, 1985, p. 34, nota e.

2 BÍBLA DE J ERUSALÉM, 1985, p. 2130 , nota $p$.

3 Thomas SPIDUK, 2002, p. 258259; e Vicenzo LOI, 2002, p. 345.

${ }^{4}$ Michel SOT, 1985, p. 13.

\section{Introdução}

Os termos carne e corpo encontram-se freqüentemente associados nos escritos medieva is ocidenta is. Esse fato pode serparcia Imente explica do pelas tradições intelectuais das quais o Ocidente é herdeiro: a judaica, na qual um único termo em hebra ico, basar, ${ }^{1}$ era utiliza do "para sublinhar o que há de fraco e perecível na condição humana e para designar o homem em sua pequenez diante de Deus"; ${ }^{2}$ e a helenística, na qual a oposição ma téria corruptível e razão inc orruptível encontrase presente no pensamento de diferentes autores, sobretudo platônicos e estóic os. ${ }^{3}$ Dessa forma, durante séculos, os med ieva is oscila ram entre, por um la do, a visão dualista do corpo associado à came e oposto à alma e, por outro, a da unidade da alma e do corpo, criados em um mesmo momento e salvos juntos do pecado. ${ }^{4}$ 
5 J oan SCOTT, 1988, p. 5.

${ }^{6}$ Estamos desenvolvendo desde 2001, com o a poio financeiro do CNPq, a pesquisa intitulada Santidade e gênero na hagiografia mediterrânica no século XIII: um estudo comparativo, que busca discutir, a partir das análises das vidas de santas e santos produzidas por Gonza lo de Berceo e Tomás de Celano, como os discursos de gênero foram apreendidos e apropriados por ta is autores na construção de padrões de santidade. 0 presente artigo apresenta conclusões parciais dessa pesquisa. Quero deixar registrado um agradecimento especial aos professores Elias Nunes Frazão, Leila Rodrigues da Silva e Maria Cristina Correia Leandro Pereira, que leram os origina is deste trabalho e apresentaram sugestões tanto quanto à forma quanto a o conteúdo. Ta mbém a gradeço a os a lunos das disciplinas Corpo, discurso e diferença no mundo ocidental, oferecida no Programa de Pós-Graduação em História Comparada no primeiro semestre de 2003, e Pensamento medieval e universidades: reflexões sobre o corpo, ministrada na graduação em História no segundo semestre de 2003. Grande parte das reflexões aqui a presenta das surgiu dos debates e das dúvidas suscitadas durante as aulas.

7 SOT, 1985; e Jean-Claude SC HMITT, 2002.

${ }^{8}$ Não vamos nos deter no estudo do século XIII, pois esse não é o objetivo deste trabalho. 0 contexto, a qui, nos serve somente como uma referência. Para uma abordagem mais detalhada desse período, ver, dentre outros, Lênia Márcia MONGEயI, 1997; Norbert ELIAS, 1994; André VAUC HEZ, 1995; Eamon DUFFY, 1998; J acques LE GOFF, 1998; J acques VERG ER, 2001; Elisa beth GAUCHER e J ean DOUFOURNET, 1998; e J osep-lgnasi SARANYANA, 1997.
Partindo do pressuposto de que "meanings are not fixed in a culture's lexic on", 5 o presente artigo tem como objetivo discutir, empregando a categoria gênero, os sentidos de corpo e came em duas obras hagiográficas escritas porGonzalo de Berceo, poeta e clérigo castelhano, na primeira metade do século XIII. ${ }^{6}$ Desejamos verificar, detec tand o a mbigüida dese conflitos, como essa ca teg oria se articula às concepções berceanas de corpo e came.

Destacamos que já foram realiza dos trabalhos que analisa ram os sentidos de corpo e carne em textos medieva is, ${ }^{7}$ porém, estes não utilizaram 0 gênero como categoria de análise e nem se detiveram no estudo das hagiografias castelhanas medievais. Dessa forma, nossa proposta distingue-se dos trabalhos anteriormente empreendidos.

Estudar a construção dos sentidos de corpo e came no século XIII reveste-se de maior interesse quando nos voltamos para as transformações que, segundo a historiografia, marcaram esse período em diferentes campos: ${ }^{8}$ a expansão da vida urbana e o maior volume de riqueza coletiva circulante; o crescente interesse, presente em diversos setores da sociedade, em regrar o corpo; o nascimento de um novo ideal de vida religiosa, que se inspirava em uma releitura da vida de Cristo e da Igreja primitiva; as novas concepções de santidade; o desenvolvimento de uma nova hagiografia; os esforços reformadores da Cúria Papal, em sua busca pela orga nização da hierarquia eclesial e por uma maior ação pastoral junto à sociedade; a luta contra a heresia, em especial a cátara, que rejeitava o corpo, visto como obra do mal; o surgimento das universidades.

Éà luz dessas transforma ções que deseja mos dic utir, neste artigo, como os sentid os de corpo e came presentes nos textos berceanos se artic ulam a os símbolos, às normas e à organização social na Península lbérica na primeira metade do século XIII.

\section{Pressupostos teórico-metodológicos}

Na a nálise dos textos hagiog ráficos selecionados, partimos de a lguns pressup ostos teónic os, cuja slinhas gera is passamos a apresentar. Primeiramente, destacamos que nosso trabalho se assenta no paradigma pós-modemo e, portanto, dentre outros pontos, realçamos a subjetividade dos sujeitose da linguagem; defendemosque a a preensão do real só é possível a tra vés dos signos, das interp reta ções, das representações; elegemos o estudo do particular, renunciando à busca pelasorigens, regularidades ou leis causais e gerais para a explicação dos fenômenos; 
${ }^{9} \mathrm{SCOTT}, 1988$, p. 44.

10 Seguimos, como Scott, a definição de poder proposta por FOUCAULT, 1987, p. 206-207.
11 Sobre os três momentos no processo de produção, materialização e difusão dos discursos, ver Eni ORLANDI, 2001.

12 Utiliza mos objetivar, aqui, no sentido empregado por Paul VEYNE, 1982, p. 162-165.

${ }^{13}$ CLARK, 2001. p. 396.

${ }^{14} \mathrm{~J}$ oël SAUG NIEUX, 1996. privilegiamos as invenções, as inconstâncias, as contra dições; problematizamos a configuração das identidades.

Em ha rmonia com esses pressupostos pós-modemos, adotamos a definição de gênero proposta por Scott: "gender is a constitutive element of social relationships based on perceived differences between the sexes, and gender is a prima ry way of signifying rela tionships of power". 9 Compreendemos que o gênero, como o poder, ${ }^{10}$ não é unific a do, não é coerente, e não se enc ontra centra liza do. Está presente em diferentes aspectos do social, ta is como as instituições, as práticas, as normas e os símbolos, que estão articulados, mas não são reflexos automáticos uns dos outros.

Vale destacar que, na perspectiva teórica que adotamos, o social não é uma totalidade organizada a partir de um núc leo que detemina seu func ionamento, mas é constituído por múltiplos discursos, que lhe dão sentido e o organizam, e que mantêm relações dinâmicas entre si. Os discursos, portanto, não são idéias que antecedem a organização social, como a pontam os pensadores idea listas, mas constituem as representações, as práticas, as relações socia is e as instituições.

Os discursos são expressos ma terialmente através das linguagens - verbais ou não verbais -, em um determina do tempo e lugar, em meio a relações de forças, e para um outro(s). ${ }^{11}$ A essas expressões denominamos enunciados, que podem objetiva $r^{12}$ ma is de um discurso e, dessa forma, a presentar a mbigüidades e inconstâncias. A única forma de reconstruir e analisar os discursos e a sua dinâmica é, porta nto, a tra vés do estudo dos enuncia dos e de sua transmissão. Ad otamos, assim, o que Elizabeth Clark denomina de "the hermeneutic paradigm": 13 tratamos os doc umentos históric os como textos e enfa tiza mos o estudo dos processos de signific a ção, pois não consideramos que existam sentidos natura is ou a tempora is.

Pa ra o estudo dos enuncia dos selec iona dosopta mos pela análise lexicográfica e semântica, seguindo a proposta de Saugnieux. ${ }^{14}$ A partir das unida des de análise - as palavras cuerpo e carne em suas diversas formas (camal, corporal, etc.), em termos correlatos (partes do corpo, por exemplo) e em sinônimos - verificamos onde e como esses termos figuram no texto, atentos a que elementos se relacionam, associam-se ou se opõem. Os dados levantados foram interpretados à luz dos compromissos e pertencimentos do hagiógrafo. 
15 Sobre a formação intelectual de Gonzalo de Berceo, ver SILVA, 2001.

16 Optamos por empregar, traduzida, a foma verbalizada de gender, em inglês, genderizing. Acreditamos que esse termo exprime o dina mismo, a complexidade e as constradições dos processos pelos quais são socialmente construídas as diferenças sexuais.

${ }^{17}$ Os manuscritos $\mathrm{S}$, datado de 1240 , o H, de 1360 , e o E, ta mbém do século XIV.

\section{Gonzalo de Berceo e as vidas de Santo Domingo de Silos e de Santa Oria}

Através de suas próprias obras e de documentos nota ria is preserva dos, é possível construir uma biografia do hagiógrafo. Ele nasceu no povoado de Berceo, localidade de La Rioja, região centro-norte do Reino de Castela, prova velmente em 1196. Foi ordenado clérigo secular por volta de 1227. Antes de sua ordena ção estudou no mosteiro de San Millán de la Cogolla, um dos ma is ricose influentes da região riojana, e, mesmo depois, já como sacerdote, manteve relações com esse cenóbio.

O caráter culto de sua produção literária permite inferirque o riojano tenha estuda do em uma escola urbana, prova velmente na Universida de de Pa lência. ${ }^{15}$ Nesse centro intelectual, com a retomada dos textos clássicos grecoromanos, novos saberes foram sendo introduzidos e os a ntigos revistos, como as concepções sobre o corpo/came.

Gonzalo de Berceo, portanto, foi influenciado, ao compor suas hagiografias, por discursos e práticas referentes pelo menos a três instituições: a cúria papal; o monaca to; a universidade. Mas que elementos incorporou e quais rejeitou? Ela borou novas formulações?

Selecionamos, dentre as obras compostas por Berceo, do is textos: a Vida de Santo Domingo de Silos (VSD) e a Vida de Santa Oria (VSO). A opção pela análise comparativa dessas obras reside no fato de narrarem a vida de santos de sexos biológicos diferentes que viveram na mesma região, La Rioja, e no mesmo período, século $\mathrm{XI}$, o que, acreditamos, permite tornar ma is visíveis as genderizações. ${ }^{16}$

A VSD apresenta a biografia de Domingo, que foi clérig o secula r, eremita e porfim ingressou na vida religiosa regular no mosteiro emilianense. Após desobedecer a ordens do rei Garcia de Nájera, exilou-se em Castela, onde se tomou abade do cenóbio de Silos, do qual, segundo a tradição, foi reformador.

Essa hagiografia foi composta por volta de 1240 , em castelhano, em 777 estrofes de quatro versos de quatorze estrofes, a chamada cuaderna via. A obra apresenta termos latinos, topoi retirados da literatura clássica e recursos literários presentes nos manuais de retóric a medieva is. Está dividida em trêspartes. Na primeira apresenta a biografia de Domingo; na segunda, seus milagres em vida e sua morte; na terceira, seus milagres após a morte. A VSD foi redigida a partir de um texto la tino do século XI, a Vita Dominici Siliensis, de autoria do monge silense Grimaldo, e transmitida por três manuscritos medieva is. ${ }^{17}$ 
${ }^{18}$ Isabel Úria Maqua defende que a VSO foi a última obra composta por Gonzalo de Berceo (ÚRIA MAQUA, 1992, p. 494).

19 É provável que narrativas de martínos de virgens, como defende John K. Walsh, também tenham influenciado a redação dessa obra (WALSH, 1972, p. 303).

${ }^{20}$ Alguns a utores acreditam que osúltimos 21 versos da VSO foram adições posteriores, provavelmente elaboradas pelo próprio autor, em uma segunda edição da obra (Joaquim GIMENO CASALDUERO, 1984, p. 236).

${ }^{21}$ MARTIN ALONSO, 1986, t. 1, p. 631 e 832.
Como os mosteiros de San Millán de la Cogolla e de Santo Domingo de Silos esta va m unidos por uma Carta de Hermandad, defende-se que esse poema foi composto a pedido do abade emilianense, que o ofertou à comunidade de Silos. Assim, é possível que a VSD tenha sido redigida para marcaro passa do comum doscenóbios, já que Domingo vivera em ambas ascasas, ou como uma espécie de homenagem a patrono do Mosteiro de Silos. Independentemente da motivação imediata para a sua redação, certamente o poema foi utilizado para festejar e lembrara memória do santo, divulgarensinamentos mora is, entreter e servir como material de estudos, tanto para religiosos como para fiéis, em leituras públicas e privadas.

A VSO relata a trajetória de Oria que, a inda criança, tomou-se reclusa do Mosteiro de San Millán de la Cogolla. Ela teve uma vida marcada pordiversas visõese uma morte prematura. Essa foi, segundo os especialistas, a penúltima obra elaborada porG onzalo de Berceo, porvolta de $1264,{ }^{18}$ ta mbém em castelhano. A fonte la tina desse poema foi uma vita, hoje perdida, elabora da no século XI porMunio, monge emilianense, segundo a própria VSO, o confessorda santa. ${ }^{19}$

Esse poema foi preservado porum únic o manuscrito medieval, o F, do século XIV. Em sua forma atual contém 205 estrofes com versos em cuaderna via, que podem ser dividida s em prólogo, introdução, primeira visã o, segunda visão, terceira visão, morte de Oria e epílogo. ${ }^{20}$ Tal como na VSD, abundam as técnicas retóricas medieva is.

É prová vel que, a o redigira VSO, Gonzalo de Berceo tenha ima ginado um público de mulheres reclusas, o que, certamente, influenciou a seleção do conteúdo e a composição dos versos, que sublinham aspectos da esp iritualidade monástic a feminina, como as vigílias e visões. Contudo, essas característic as não limita ram o público do poema, que, prova velmente, fo i divulga do entre diferentes grupos, a fim de despertar a veneração a Oria.

\section{Cuerpo e carne na VSD e na VSO: análise lexicográfica e semântica}

Segundo Martin Alonso, o termo castelhano cuerpo provém do latim corpus e, no século XIII, significava a matéria orgânica dos homens e animais; qualquer coisa que tenha extensão limitada e seja perceptível, e como sinônimo de cadáver. Quanto à carne, do latim caro, carnis, era usado para designar a parte muscular de homens e bichos; a parte comestível de certos a nimais; 0 corpo mortal, especialmente o humano, em oposição ao espírito. ${ }^{21}$ Mas como os textos berceanos dão sentidos a essas pala vras? 
Osvocábulos cuerpo e carne são empregados ta nto na VSD quanto na VSO. Na VSD o termo cuerpo figura trinta e c inco vezes. Desta socorrências, seis referem-se a o c orpo de Domingo em vida; quatorze após a sua morte, quando já era considerado santo; sete designam corpos de outros santos; sete de outros personagens e em uma o termo compõe uma reflexão sobre o corpo e a alma. Quanto ao termo carne, ele figura como substantivo quatorze vezes, e na sua forma adjetiva, carnal, quatro vezes. Dentre estas ocorrências, sete referem-se a o santo em vida, três a pós a sua morte, seis estão relacionadas a outras pessoas, em uma o termo designa um alimento e em outra é colocado a o lado de cuerpo na reflexão já menciona da.

Como é possível verificar só por esse levantamento quantita tivo, o uso do termo cuerpo predomina, no conjunto da VSD, a o tratar de corpos de santos: vinte e uma, ou seja, $60 \%$ das referências estã o relac iona dasa santos a pós a morte; qua torze, $40 \%$, a corpos de santos em vida, sendo que, destas, só em $17 \%$ o corpo em questão é do silense.

Com o termo carne observamos o contrário: ele é usado $72 \%$ das vezes em relação a personagens ainda em vida; destas ocorrências, $55,5 \%$ designam especificamente o silense, mas em $16,6 \%$ referem-se a Domingo após a sua morte, mas como sinônimo de cadáver. Vale sublinhar que o termo nunca denomina corpos de pessoas mortas já reconhecidas como santas.

$\mathrm{Na}$ VSO, o termo cuerpo é usado sete vezes. Em quatro, trata do corpo de Oria em vida; em duas, do seu corpo a pósa morte; e em uma refere-se a o corpo de Cristo. Aqui já se percebe uma diferença em face da VSD: em $57 \%$ das vezes em que o termo cuerpo está presente no texto relaciona-se a o corpo vivo da monja. Só em $28,5 \%$ refere-se a o corpo da reclusa após a morte, já santificado. O termo carne figura nove vezes, e só como substantivo. Destas referências, seis estão associadas a Oria em vida, ou seja, $67 \%$, e três, $33 \%$, a outros personagens, também vivos. Como na VSD, carne é um termo que nunca designa corpos santificados.

Vamos ampliar nossas reflexões para o campo semântic o: em todas as passagens os termos cuerpo e carne ganham o mesmo sentido? A que outras palavras cuerpo e carne se associam ou se opõem em cada uma das obras? Vejamos.

Na VSD o termo cuerpo é empregado em diferentes sentidos, inclusive compondo expressões. Assim, cuerpo é usa do como sinônimo de cadáver (VSD 528, 529, 531, 532); junto à palavra sanc to denomina os locais onde as pessoas consid era das venerá veis esta va m sepulta das (VSD 98, 118, $158,267,271,274,283,286,574,575,596,612,614,618$, 
22 Para Olegario García de la Fuente, que estudou o vocabulário bíblico empregado por Berceo, carne é usado pelo poeta como sinônimo de cuerpo, ou seja, como matéria orgânica do homem, e, em sentido valorativo, como a natureza humana inclinada a o mal. Concordamos parcialmente com o autor. O uso do termo carne, em Berceo, é múltiplo, suscitando, inclusive, a mbigüidades, como veremosno decorrer da a nálise (GARCIA DE LA FONTE, 1992, p. 92).

${ }^{23}$ Em uma dessas referências, cuerpo designa tanto o corpo da santa protagonista como o de sua mãe (VSO 183).
641, 544); na expressão cuerpo palaciano, utilizada em VSD 485a, significa homem excelente, excepcional. Já a palavra carne é usada para indicar o alimento (VSD 55); como sinônimo de cadáver (VSD 527 e 664); para ressalta r a humanida de de C risto (VSD 62a); na exp ressã o omne de carne, signific ando humano (VSD 234d e 490a); para referirse a pessoas da mesma família (VSD 563ab). ${ }^{22}$

Das seis referências sobre Domingo em vida em que é usa do o termo cuerpo, em qua tro o a utordá informações sobre como o santo relacionava-se com o seu próprio corpo. Nas outras duas, em VSD 485a, a expressã o cuerpo palaciano, já ressaltada, é empregada para referir-se a Domingo como um epíteto, e em VSD 489b para narrar o momento da morte do santo. Nas sete em que o vocábulo carne é utilizado, só em VSD 120 não retra ta a relação do silense com o seu corpo, mas com Deus, que o deixava cada vez ma is próximo do espiritual e distante do material: "Diole tamanna graçia el Rey çelestial,/ que yá non semeiaba criatura mortal,/ Mas o angel, o cosa, que era sp irital/ Que vivie con ellos en figura camal".

Em a lguns versos o autor não usa o termo cuerpo, mas faz referência a partes do corpo. Assim, em VSD 12, o narrador menciona os olhos e os "lábios da boca" do silense, mantidos sempre sob controle, mesmo quando ele era uma criança, para não dar espaço ao pecado. Em VSD 86 e em 89d, para sublinhara disciplina que Domingo impunha a seu corpo quando ingressara na vida monástica, faz-se nova mente a lusão a os olhose à boca, que estavam constantemente sob vigília, e destaca-se a cor amarela de sua tez, típica de um homem sofrido.

Na VSO há somente duas estrofes em que o termo cuerpo é usa do para retratara relação de Oria com seu corpo: em VSO 15d e em VSO 102, nas quais o corpo é associado a o sofrimento. Em VSO 107 e 111 destaca-se o retomo de Oria ao corpo após suas visões, sendo assim o termo usa do como sinônimo de ma téria física. Em VSO 132 e 136 se refere ao corpo morto da santa como digno de ser adorado. ${ }^{23}$ Quanto a o termo carne, todas as vezes em que figura na obra está associado a luta, a domínio, a esforço, a contenda.

Há um da do curioso na VSO. Grande parte da ação do poema desenrola-se nas visões da santa, em que ela é transportada ao céu sem seu corpo (VSO 98c e 108c). Contudo, sua a parência, suas ações e suas sensações continuam a ser corporais: sobe uma escada (VSO 39), deleita-se com a sombra de uma árvore (VSO 43-45), conversa com as virgens que a guiam e com as pessoas que encontra (VSO 47, 90, 125, etc.), é saudada com abraços (VSO 64), sente a maciez de um tecido (VSO 128- 
130). Ou seja, Gonzalo de Berceo não consegue retrata ra alma da reclusa sem dotá-la de uma dimensão corporal.

Como na VSD, Gonzalo de Berceo ta mbém menciona na VSO partes do corpo para realçara disciplina que Oria impunha a seu corpo. Nesse sentido, em VSO 16 lemos que a monja "Con a mbos sus labriellos a pretaba sus dientes,/ Que non saliessen dende palabras desconvenientes". As dores que ela sentia em sua enfermidade também são expressas por meio de partes do corpo: batia em seus peitos, gesto tradicionalmente associado à mulher, e levanta va as mãos (VSO 138cd). E o no momento da sua morte, o da entrega suprema, seus gestos, muito similares aos de Domingo (VSD 521), pois se trata de um topos, são detalhados (VSO 176bc, 177).

E como Domingo e Oria se relacionavam com os corpos dos outros? A VSD informa que a tra vés da interc essão do abade vá rios corpos foram cura dos (VSD 306, 418). Em muitos casos, a cura operou-se através de gestos e/ou toques corpora is do santo (VSD 342, 344, 394, 478). Contudo, nem sempre Domingo buscou a cura de um corpo. Em VSD 419-433 é narrada a história de Garcia Munnoz. Este homem enriquec era roubando os cerea is dos seus vizinhos. Apesar de conselhos do santo e de suas promessas de redimir-se, ele voltou a furtar. Assim, seus vizinhos rec orreram a Domingo, que orou porMunnoz, cuja "la fuerza del cuerpo fué toda amortida" (VSD 426d). O homem recorreu ao abade, que the fez um longo discurso, do qual o ponto culminante encontra-se na estrofe 432: "Mas vale que enfermo a paraiso vayas,/ Que sano e valient en el infiemo cayas,/ Conviene que lo sufras, maguer laçerio trayas,/ Ca de tomar qual eras esperanza non ayas".

Domingo também se relaciona com corpos de pessoas já consagradas como santas após a sua morte, venerando-as. Em momentos de dificulda de orava no local onde estava sepulta do San Millán (VSD 98c, 118a, 158a) e partic ipou do cortejo que a companhou, a té o mosteiro de San Pedro de Arlanza, os corpos de São Vinçençio, Santa Sabina e Santa Cristeta, irmã os que foram ma rtiriza dos por volta de 304 e cujos restos morta is se encontravam na cidade de Ávila.

Na VSO, Oria estabelece contatos com outros personagens, como sua mãe e Munio, seu confessor, mas ta is relações não implic aram conta tos físic os ou curas. 0 único contato corporal da reclusa registrado nessa obra são os abraços com que é saudada no céu em uma de suas visões (VSO 64), quando, paradoxalmente, como a própria obra afirma, a monja estava fora do corpo (VSO $98,108)$. 
${ }^{24}$ Carla CASAGRANDE e Silvana VECCHIO, 2002, p. 341.

${ }^{25}$ MARTIN ALONSO, 1986, t. 2, p. 1579

\section{Cuerpo e carne nos textos hagiográfic os berceanos: algumas interpretações}

A seg uir, vamos a presenta ra lgumas reflexões sobre os sentidos de cuerpo e carne nos textos bercea nos VSD e VSO, a tentos aos processos de genderização, às a mbigüida des, às inter-relações, às inconstâncias. Essas reflexões se concentra ram em cinco pontos: o controle do corpo, a luta contra a came, a corporalidade de Oria, a dorfísica e a relação corpo e alma.

\section{0 controle do corpo}

A partir do século XIII, segundo Casagrande e Vec chio, o corpo deixou de ser, no Ocidente, visto como "fonte de pecado, tomando-se simplesmente campo de ação, matéria maleável de uma forma pecaminosa". ${ }^{24}$ Assim, passou a ser considerado como algo genérico e neutro, pois, por si só, não poderia ser bom ou mal. Ou seja, ele passou a ser apreendido como o locus para o pecarou para o resistir a o pecado. Enos textos berceanos?

Vamos nos deter, primeiramente, na interpretação dos versos que tratam da relação entre Domingo e seu corpo. Em VSD 41, quando ele se preparava para ingressar na vida religiosa secular, afirma-se que o silense "ponie sobre su cuerp o una g graves sentenç ias,/ leiunios, e vig ilias, e otras abstinençias", e com um objetivo: "Guardabase de yerros, e todasfallençias,/ Non falsarie pornada las puestas convenençias".

Segundo Martin Alonso, a palavra sentencias, no castelhano do século XIII, possuía múltiplos significados: pa recer, pena, castigo, governo, administração, a ssunto, negócio. ${ }^{25}$ Ao usartal termo, Gonza lo de Berc eo certamente queria realçar o poder exercido pelo santo sobre o seu corpo, submetendo-o a rigorosa disciplina. Ou seja, Doming o governa, administra, castiga o seu próprio corpo, controlando o seu sono, a sua alimentação e abstendo-se de outros itens.

Essa idéia é retomada em outros versos. Segundo VSD 226a, Doming o possuía "un cuerpo tan lazra do", pois, como lemos em VSD 397cd, ele estava sempre "Fa çiendo gran ieiunio, cutiana oration,/ Sufriendo en su cuerpo muy grant afliction". Toda essa disciplina tinha um escopo: "qui porla a Ima el cuerpo aborriste" (VSD 767a). Nesse sentido, a relação do monge com o seu corpo, segundo a VSD, é marcada pela busca do autocontrole. Para não pecar, o abade impunha-se restrições, sobretudo no campo da alimentação e do sono. Essa a titude redundava em sofrimentos - fome, fraqueza, cansaço -, mas funcionava como uma espécie de barreira ao pecado. 
${ }^{26}$ Optamos portransc revero texto da Bíblia em língua portuguesa na versão de João Ferreira Almeida, pois se trata de uma tradução da Vulgata, a versão oficial utilizada pela Igreja na Idade Média. Segue o versículo segundo a Vulgata: "vidit igitur mulier quod bonum esset lignum ad vescendum et pulc hrum oculis aspectuque delectabile et tulit de fructu illius et comedit deditque viro suo qui comedit" (BÍBLIA, 1999).

27 Essa expressão ta mbém é empregada em VSD 86c.

${ }^{28}$ MARTIN ALONSO, 1986, t. 2, p. 1517.

${ }^{29}$ MARTIN ALONSO, 1986, t. 2, p. 1434.

30 MARTIN ALONSO, 1986, t. 2, p. 1158.

${ }^{31}$ Mario PILOSU, 1995, p. 45-58.

32 PILOSU, 1995, p. 54.

Como assinalamos, o texto berceano realça a lguma spartes dos corposdos santos biografados. Na VSD, os olhos, os lábios, a boca, as mãos e a cabeça são mencionados. Contudo, a o tratar do govemo do corpo, dá-se um maior destaque aos olhos e à boca. Porquê?

No relato sobre a queda do homem, presente no Gênesis, capítulo 3, redigido por volta do século $X$ a.C., mas que se manteve referencial por todo o medievo, o olha ré considera do um caminho para o pecado. Segundo esse texto, "vendo a mulher que a árvore era boa para se comer, agradável aos olhos e árvore desejável para dar entendimento, tomou-lhe do fruto e comeu e deu ta mbém a o ma rido, e ele comeu" (Gn 3,6). ${ }^{26}$ Os olhos, portanto, na trad ição juda ico-cristã ocidental, a caba ram associa dos diretamente à tentação e, por extensão, ao pecado.

Gonzalo de Berceo, como clérigo, certamente estava familia riza do com tal tra dição. Nesse sentido, é compreensível que Domingo figure no poema berceano com os olhos a perta dos e volta dos a o chão. Em VSD 12ab é feita uma relação direta entre a disciplina do olhare a luta contra o pecado: "Traie en contra tierra los oios bien premidos,/ por non catar follias tenia los bien nodridos". Há que ressaltar os termos empregados pelo autor para caracterizar o controle do olhar pelo silense nestes versos: os olhos são bien premidos, ${ }^{27}$ bem a perta $\operatorname{los}^{28} \mathrm{e}$, so bretudo, bien nodridos, bem educa dos, ${ }^{29}$ a fim de não catar follias, ${ }^{30}$ ou seja, buscar loucuras.

Quanto à boca, ela está, na VSD, relacionada aos atos de comere de falar. No medievo, como demonstrou Pilosu, diferentes a utores, tanto monásticos como universitá rios, acreditavam que a comida e a bebida em excesso, a lém de configura rem a gula, estimula vam outros pecados, sobretudo o sexual. ${ }^{31}$ Ou seja, os excessos cometidos pela boca poderiam gerar o "desencadeamento, no sentido do desa parec imento dosfreios mora is". ${ }^{32}$ Para sanar ou prevenir-se de tais faltas, os eclesiásticos recomendavam o jejum, a sobriedade e as vigílias. Seguindo esse pensamento, na VSD, para vencer as tenta ções, Domingo disciplina o seu corpo com orações, abstinências e silêncio, traços fundamenta is da espiritualidade monástica que, na VSD, se tomam estratégias na busca pela disciplina corporal.

Oria ta mbém disc iplina va seu corpo (VSO 15d, 120), mas, diferentemente de Domingo, atento, sobretudo, ao olhar e à alimentação, ela submete a fala à disciplina. Assim, a VSO apresenta uma estreita junção entre fala e asc etismo, que fic a patente logo na primeira visão de Oria, quando ela encontra a personagem alegórica Voxmea (nome la tino que traduzido significa voz minha) guardando 
${ }^{33}$ Cf. também VSO 147-148.

${ }^{34}$ WEISS, 1996

${ }^{35}$ WEISS, 1996, p. 448.

${ }^{36}$ Christiane KLAPISC H-ZUBER, 2002, p. 145. seu futuro trono celeste. Ou seja, é a voz da monja, a sua fala, que lhe assegura o trono (VSO 90). Dessa forma, qua nto mais se aproxima a sua morte e, portanto, a sua vitória final contra o pecado e a came, a sua voz vai ficando embarga da e a intermediação do confessor é exigida. ${ }^{33}$

Porquê? Para Julian Weiss, esse controle da fala na VSO é proposital e fruto de uma construção de gênero. ${ }^{34}$ Segundo esse autor, na VSO, Gonzalo, como narrador, a utoridade clerical e masculina, a propria-se da experiência espiritual de Oria, fazendo-a calare falando por ela..$^{35}$ Essa ação fica ainda mais evidente quando, ao retratar a conversa entre a monja e Munio, seu confessor, o hagiógrafo identific a o na rradora esse personagem e passa a fazero rela to em primeira pessoa: "La madre de la dueña/ fizo a mi clamar,/ fízome en la casa/ de la fija entrar,/ yo que la afincasse/ si podiese fablar,/ ca querié dezir algo" (VSO 149).

A fala contida é, na VSO, a expressão maior do controle do corpo e signo de uma grande renúncia. ${ }^{36}$ Estando reclusa, sem ter a cesso a o luxo, a os manjares, a os tecidos delicados, a sua fala, meio pelo qual se comunicava com o mund o exterior, toma-se o seu principal obstáculo na busca por uma vida irrepreensível. Mas não é sozinha que Oria controla a sua fala. Essa tarefa cabe aos clérigos - o confessor Munio e o narrador da VSO que ouvem as palavras da monja e se apossam delas, registrando-as para a posteridade.

Dessa forma, no que tange a o controle do corpo, há um elemento diferenciador na VSO em face da VSD: Oria disciplina sobretudo a fala e, para isso, conta com um confessor, um homem que a acompanha, a aconselha e está a o seu lado a té a sua morte. Já Domingo, sem qua lquer ajuda humana, consegue manterseu corpo sob disciplina. O gênero, porta nto, a inda que parcia Imente, partic ipa, no texto berceano, das relações estabelecidas pelos santos com seus próprios corpos.

Nos textos berceanos o corpo também é considerado neutro. Contudo, como é no e com o corpo que se peca, estimula-se na obra, pelo exemplo dossantos protagonistas, a disciplinar o corpo submetendo-o a restrições. Assim, a pregoa-se a abstinência de comida, de bebida, do sono e estimula-se a o silêncio e a o controle do olhare da fala. Ainda que partilhando de uma visão positiva do corpo, Gonza lo de Berceo recupera práticasmonásticas e as apresenta como táticas para manter o corpo longe do pecado. Ao fazê-lo, fez recair sobre os homens a responsabilidade de regular seus corpos e de auxiliar as mulheres a disciplina rem os seus. 
${ }^{37}$ SCHMITT, 2002, p. 256.

${ }^{38}$ GARC IA DE LA FONTE, 1992, p. 242 e 254.

\section{A luta contra a came}

A came, como aponta Schmitt, "é um valor, tanto como uma coisa: a came recebe um papel ético e na história da salvação ela é o ator principal". ${ }^{37}$ E nas obras em a nálise?

Como já assinalamos, carne e cuerpo eram usa dos como sinônimos no castelhano do século XIII, mas ta mbém reserva va m signific a dos partic ula res. Nas obras bercea nas o termo carne jama is é empregado para designaroscomos cuja santidade já fora reconhecida. Esse dado pode ser uma pista de um desses sentidos particulares.

Nos versos da VSD em que é usa do o termo carne, é possível enc ontra r um dup lo sentid o. Em VSD 67d, 68b, 80b e 414, o autor reforça a idéia de que o abade mantinha sua came sob disciplina, o que aproxima o sentido do uso dessa palavra ao de cuerpo, tal como apresentamos no item anterior. Em dois outros versos, porém, carne é associada a vocábulos que apontam para o significado de opressão e de conflito. Nesse sentido, em 247d, a vida terrena é caracteriza da como uma "camal prision", e em VSD 250a a came, unida a o diabo, quer tirar o abade de seu caminho rumo à salvação.

Se a palavra carne, nesses versos, não pode ser considerada como simples sinônimo de corpo físico, matéria orgânica, o que mais significa? Na VSO também encontramos outros usos para carne?

$\mathrm{Na}$ grande maioria dos versos da VSO em que o termo carne figura é para referir-se a os cuidados da monja com sua própria carne, e o sentido gerado é de conflito e de opressão, tal como em alguns versos da VSD. Em VSO $15 c$, lemosque Oria luta va constantemente com sua came. A perspectiva de batalha evidencia-se ainda ma is quando verificamos que o verso seguinte informa que o combate esta belec id o contra a ca me visa va não dar consentimento a o corpo. Assim, perguntamos, qual a relação entre combater a came e controlar o corpo?

A idéia de oposição à came é também destacada na VSO, nos versos $17 \mathrm{~cd}$ e $112 \mathrm{a}$, com o uso do verbo martiriar. Segundo Garcia de la Fonte, ${ }^{38}$ esse termo surgiu no século VI e representa uma transformação semântica em face do termo bíblico mártir, que significava testemunha. Em um primeiro momento foi usado com o sentido real e metafórico de matar, e no decorrer do med ievo, com a a firma ção das línguas românicas, passou a serempregado com o significa do de reprimiras paixões. Martiriar a came traz, também, o sentido de repressão, conflito, luta. 
${ }^{39} \mathrm{Na}$ segunda visão de Oria, Maria vem visitá-la. As virgens a precedem, dando a Oria um leito de seda, que é recusado pela monja: "Lecho quiero yo aspero de sedas a guijosas./ Non merçen mis ca mes iaçertan viçiosa s:/ Por Dios que non seades en esto porfidiosas,/ Para muy grandes omnes son cosastan preçiosas".

${ }^{40}$ Esse verso refere-se a os pais de Oria, que renunciaram ao casamento e passaram a viver como reclusos.

${ }^{41}$ Certamente essa concepção de came como vontade pode permitir uma conexão com a psic análise. Contudo, nosso instrumental teórico, calcado na perspectiva pós-modema, rejeita modelos explic a tivos universa is e a temporais, tais como os propostos pela psicanálise.
Em outros versos, a idéia de carne como sinônimo de cuerpo é mantida a tra vés do destaque da do à disciplina a que o físico era submetido: Oria controla e prepara sua carne para serdigna de subir a os céus (VSO 36cd); não dá misericórdia a sua came para não perder a vitória (VSO $111 c d$ ); nã o concede à ca me qualquer sa tisfa çã o, mesmo que oferecida pelas virgens mártires que lhe aparecem em visã o (VSO 130). ${ }^{39}$

Ou seja, certos usos do termo carne nas obras em estudo, em sua forma substantiva, pressupõem uma coisa que age de forma ativa e constante na pessoa, incitandoa, esc ra viza ndo-a; é a lgo difícil de conter e, porta nto, deve ser combatido. Dessa forma, acreditamos que o termo carne, no texto berceano, tem, dentre seus múltiplos sentidos, a idéia de vontade, de impulso, de força motriz para o pecado, que deveria ser constantemente refreada, a fim de não sair vencedora.

Esse sentido evidencia-se ainda mais quando verificamos os versos em que esse termo aparece relacionado aos eremitas, tanto na VSD quanto na VSO: "tuvieron en el mundo la carne apremida" (VSO 54c), "domaron suscamesa la mayormedida" (VSO 92c), "nunca querian sus cames mantener a grant viçio" (VSO 13a) ${ }^{40} \mathrm{e}$ "por quebrantar sus carnes façense ermitas,/ tienen las volunta des en corazón mas fitas" (VSD 63bc). Em to dos esses versos desta ca-se o caráter desesta biliza dor da came, do desejo que move as "voluntades" e que, portanto, deve ser domado, combatido, vencido. ${ }^{41}$

Ainda que Gonzalo de Berceo utilize em algumas passagens o termo carne com acepções iguais às de cuerpo, essa palavra possui um uso particular. Dessa forma, c arne só é usa da para referir-se à ba talha travada por uma pessoa consigo mesma. Ou seja, nos textos berceanos, é impossível lutar contra a came/vontade de outrem. Essa interpretação também explica por que o vocábulo carne nunca é usa do para referir-se a os corpos mortos dos santos já reconhecidos como veneráveis: eles já obtiveram sua vitória derradeira sobre a came.

Gonzalo de Berceo, em alguns versos, parece associar, negativamente, o corpo à carne, idéia muito presente em círculos monásticos medievais. Porém, c ertamente por influência dasnovasconcepções de corpo que circulavam no Ocidente no século XIII, faz uma distinção entre o corpo ma terial, neutro, e a ca me, impulso para o pecado.

Nos textos berceanos, se o corpo físico deve, e pode, ser controlado, a came - a vontade -, força destruidora, deve ser constantemente combatida. Ou seja, a came induz o homem a pecar. Por isso, luta-se contra a came, 
${ }^{42}$ Edmundo ERNESTO DELGADO, 2003, p. 283.

${ }^{43}$ SAUSBURY, 1986, p. 280.

${ }^{44}$ Cla ude THOMASSET, 1992, p. 64.

${ }^{45}$ Thomas LAQUEUR, 2001, p. 1415. busca-se reprimi-la, vencê-la, não lhe concedendo qualquer espaço. Quanto ao corpo, este é colocado sob vigília, é disciplina do para não estar disponível a o impulso da came/vontade.

\section{A corporalidade de Oria}

Outro aspec to a destacaré a corporalidade de Oria. Ao compararmos os textos fic a patente o caráter ma is corporal de Oria em face de Domingo. Mesmo em suas visões, quando a emparedada está "fora de seu corpo", sua presença ganha contornos corporais. Quanto a Domingo, pela sua grande espiritualidade, conforme VSD 120, nem parecia uma criatura mortal, mas um anjo ou outro ser espiritual.

Esse dado pode ser explicado ao nos remetermos aos Padres da Igreja, que mantiveram forte presença no pensamento hispano-cristão medieval. Profundamente influenciados pela filosofia platônica, esses teólogos possuía m uma visão dualista do mundo. Nesse sentido, para ta is a utores, havia uma nítida separação entre o material, que era associado a o sexual, e o espiritual. ${ }^{42}$ Segundo J oyce Salisbury, coube a Ambrósio e a Jerônimo transportar tal visão de mundo para os gêneros: "Men represented the mind as well as the dominant head of the household and belonged to the spiritual rea Im. Women, on the other hand, were of the physical realm. They were camal and sexual within themselves by nature... Men were by nature closer to the spiritual...". ${ }^{43}$

Ou seja, a mulher ficou associada ao corpo e o homem ao espírito. Essa idéia foi reforçada no século XIII, quando, segund o Thoma sset, ${ }^{44}$ a fisiologia do corpo feminino encontrava-se no centro dos deba tes e estudos de medic ina. Pautados nos escritos médicos antigos, os intelectua is med ieva is exp lic a va $m$ as diferenç as corpora is entre homens e mulheres pelos seus distintos graus de calor vital. Assim, acreditava-se que homens e mulheres possuíam os mesmos órgãos sexua is, só que os dos homens eram extemos e os das mulheres, internos, pois os corpos se diferencia vam pelo grau de desenvolvimento: enquanto os corpos dos homens eram considerados como o padrão ideal, a "perfeição metafísica", e, portanto, ma is próximos de Deus e do espiritual, os das mulheres eram vistos como produtos incompletos, a meio caminho dessa perfeição, e, conseqüentemente, menos desenvolvidos e mais presos à matéria. ${ }^{45}$ Não mais pautados em uma visão dualista, mas hierárquica do mundo, os pensadores cristãos da Idade Média Central associaram as mulheres novamente a o como, elemento mais concreto e sensível, e os homens à razão. 
Como hispano, dotado do saber monástico e universitário, Gonzalo de Berceo certamente entrou em conta to com ta is enunciados e acabou por incorporá-los aos seus trabalhos. Ele não apresenta, em suas obras, reflexões teóricas sobre a natureza dos corpos femininos e masculinos, contudo apreendeu tais idéias e aplicou-as na sua caracterização da santidade de Oria e Domingo. Dessa forma, a inda que buscando viver próxima de Deus, como virgem consagrada e reclusa, Oria era mulher e, portanto, considerada ma is sensível, ma is emotiva, e ma is apegada a corporal que Domingo.

Uma certa ambigüidade, porém, é perceptível na VSO. Oria, que possui uma presença corporal ma is marcante que a de Domingo, contraditoriamente, não mantém conta to físic o direto com outros corpos. As únic as menções a uma proximidade corporal, já assinalada, são os abraços que recebe no céu, quando a personagem está "fora do corpo".

As construções de gênero podem explicar essa aparente contradição. Justamente por ser mulher e, portanto, ser vista como ma is próxima à matéria, a monja, por almejar a salvação, buscou distanciar-se do mundo ma teria l: a o to ma r-se rec lusa iso lou-se, entregou-se à svisões celestiais e limitou seus contatos com outras pessoas. Disciplinando o seu corpo, com a ajuda divina e de seu confessor, a reclusa buscava vencera came para serdigna do céu.

${ }^{46}$ Georges DUBY, 1989, p. 161165.

\section{A dor física}

Ainda no que se refere a os sentidos de corpo/came nos textos berceanos, há que sublinhar a valorização da dor física presente nessas obras. Destacamos duas passagens: em VSO 135-136, na qual a enfermidade anunciada de Oria é vista como uma bênção, e a já menciona da doença de Garcia Munnoz, descrita em VSD 419-432.

Essa valorização da dor física não é exclusiva dos poemas berceanose figura em vários textos do peńodo. Duby examinou a questã $0 .{ }^{46}$ Para esse autor, até o século XII não se deu a tenção à dor no Oc id ente medieval, a pesar de sua presença cotidiana. Quando figurava, o sofrimento era visto como castigo ou associa do a os considera dos fracos, como as mulheres, as crianças, os velhos e os doentes. Com a descleric a lização e a vulga rização da cultura e o crescimento da religiosida de cristocêntrica, a dor, segundo Duby, passou a ser progressivamente percebida.

No tocante ao texto berceano, discordamos parcialmente da hipótese do renomado historiador. Defendemosque, mais do que se tomar alvo de atenção, 
o texto berceano apresenta uma nova compreensão do sofrimento, não mais considerado como fraqueza ou castigo, mas como uma dádiva. Sem dúvida, um prêmio dado aos ma is fracos, passíveis de dar espaço à came, mas visando a sua salvação eterna. Essa nova compreensão pode ser explicada por múltiplas razões, incluindo as apontadas por Duby, mas também, dentre outros fatores, pela retoma da dos textos médicos antigose a tra dução e entrada, no Ocidente, de textos de medicina muçulmanos; pela valorização do corpo; pelo maior crescimento urbano, etc.

A enfermida de de Oria, desc rita na VSO, auxilia, pela debilidade física e pela dor, o controle do corpo, em especial, da fala. Como a mulher era vista como ma is próxima da matéria e ma is fraca e, portanto, mais susc etível ao pecado, e, sozinha, não poderia combater a came, o corpo doente é uma dádiva divina que assegura a vitória sobre os impulsos da carne/vontade e dá garantias para a futura conquista da salvação.

Quanto à enfermidade de Garcia Munnoz, esta foi fruto da oração do silense, contudo, não motivada por um sentimento de vingança, mas por compaixão. Doente, Munnoz não teve forças para continuar roubando os seus vizinhos e, por extensão, não ir para o infemo, como fica evidente nos versos fina is da estrofe 426. Nesse sentido, o sofrimento corporal toma-se positivo e um meio eficaz para alcançar o céu, como já assinalamos no caso de Oria.

Na perspectiva de Gonzalo de Berceo, os sofrimentos nã o sã o meros fenômenos na tura is e podem sercredita dos a Deus. O poeta não vê, portanto, oposição entre a natureza e a ação e intervenção divina nos corpos. Longe de serem percebidas como negativas, as dores e as doenças são presentes de Deus que auxiliam homens e mulheres na luta contra a carne. Ao enfraquecer o corpo, este se torna mais dócil e fácil de ser disciplinado e, portanto, mais resistente contra os impulsos da came. Ao conferir valor positivo a o sofrimento físic 0 , o hagiógrafo 0 legitima e o apresenta como um instrumento decisivo na luta contra a came e na regulação do corpo.

\section{O corpo e a alma}

Os sentid os de cuerpo e carne nos textos berceanos também estão relacionados à concepção de alma. Essa questão fica patente sobretudo no episódio em que Domingo, a pesarde ter partic ipa do do traslado doscorpos dossantos mártires de Ávila, não a proveitou a oportunida de para levar relíquias para sua comunidade (VSD 276). Ao retornar ao Mosteiro de Silos com as mãos vazias, foi critic a do pelos monges de sua comunidade (VSD 280). 
${ }^{47}$ GAJ ANO, 2002, p. 452.

${ }^{48}$ RODRIGUES, 1999, p. 55.
Essa crítica ind ic a que os corpos dos sa ntos possuíam va lor para a quele grupo. Eles a c redita va m que as relíquias eram objetos sa gra dos, imbuíd os de poderes divinos, como, por exemplo, os de cura. Além disso, quanto mais relíquias um cenóbio ou igreja possuísse, ma is peregrinos a tra iria e, por extensão, ofertas. O conflito é finaliza do por Domingo, que a firma que "Si vos a Dios lea les quisieredes seer, Et los sus manda mientos quisieredes tener,/ El vos dará reliquias, que veredes plaçer" (VSD 282abc).

O valorda relíquia na Idade Média residia na crença de que os corpos dos santos eram uma espécie de ponte para o espiritual. Contudo, mais do que um elo entre os homens e Deus, como a firma Sofia Boesch Gajano, "o corpo do santo testemunha a possibilidade de uma unidade entre o homem e o divino que a morte não poderia interromper, apenas reforçar". ${ }^{47}$ Esse fenômeno é explicado pelo a ntropólogo J osé Carlos Rodrigues: pa ra os medieva is havia uma "lógica de indistinção metonímica entre as virtudes do corpo (no caso, um fragmento de cabelo, sangue, osso) e as virtudes contidas na alma dos santos". ${ }^{48}$

Acreditamos, contudo, que essa lógica, no texto berceano, não se limita aos corpos dos santos. As táticas para controlar o corpo e lutar contra a came, a dádiva do sofrimento e a valorização alcançada pelas relíquias assentam-se, nesses poemas, na compreensão de que espírito e matéria não se opõem, pois o corpo continha a alma.

No pensamento bercea no não só o corpo e a alma se complementam, como é no corpo que a alma se exprime. Mesmo Oria, considerada mais fraca e mais próxima a o material, com a ajuda doshomense do próprio Deus, pôde alcançar a vitória contra a came no corpo, salvando a sua alma.

Quand o o corpo é disc iplinado, a a lma é fortalecida; quando a luta contra a ca me é perdida, a a lma conta minase com o pecado; a dorenfraquece o corpo para forta lecer a a Ima; o corpo e a alma dos santos garantem a ligação do material com o divino (VSD 767).

Na perspectiva dos textos berceanos, para não cair em erro e não perder a salvação, há que manter o corpo regrado e, por extensã o, a alma livre do pecado. o corpo não pode ser, de forma alguma, impedimento para a redenção a o darlugarà came/vontade. Se o corpo tomarse um empecilho, clama-se a Deus pela dor ou enfermidade para enfra quecê-lo e a fastá-lo do impulso da carne.

O corpo, na busca pela salvação, é visto como um elemento neutro, mas, se nã o ford isciplina do, pode deixa rse levar pela carne/vontade, chegando a pecar e 
condenando a alma. Ao final, não é o corpo que será julgado, mas a alma, que como prêmio reencontra rá seu corpo redimido ou, como punição eterna, com seu corpo irá sofrer no inferno. Assim, não se trata de uma dicotomia alma/corpo, mas da compreensão de que é no corpo que a alma perde ou ganha a batalha contra o pecado.

\section{Conclusões}

Em nosso artigo, procuramos demonstrar que, a o retratar as relações dos santos com seus corpos e com os de outros, os textos berc ea nos ma teria liza m a a preensã o e a apropriação de discursos constituintes da sociedade ibérica no século XIII.

Certamente o objetivo de Gonzalo de Berceo, ao redigir a VSD e a VSO, não era tratar teoricamente das interações das pessoas com os seus corpos ou traçar reflexões sobre os sentid os de cuerpo/c arne, mas estimular - culto a Santo Domingo e a Santa Oria, incluindo ensinamentos morais e doutrinários, ilustrados pelos a tos dos prota gonistas. Porém, a o fa zê-lo, a cabou por elaborar objetivações sobre o mundo social.

$\mathrm{Na}$ composição dessas obras, o poeta riojano foi influencia do por referencia is diversos - a Bíblia; as reflexões filosófic a s; os elementos funda menta is do credo cristão; a tra dição patrística; os novos a portes universitários; as concepçõesteológicasda Igreja Romana - que apreendeu e selecionou na construção de um texto repleto de sentidos. A hagiografia berceana, portanto, não ficou imune aos diversos discursos que compunham o social no momento em que foi redigida.

Apesar de encontra rmos nos esc ritos de Gonzalo de Berceo em estudo uma certa imprecisão no uso dos vocábulos cuerpo e carne, é possível, contudo, identificar uma clara distinção de significa dos. O corpo, visto como a parte física do homem e liga do à alma, é, para o riojano, - local em que se estabelece a luta contra a carne/ vontade. Se esta vencer, a alma e o corpo são derrotados. Se o corpo for disciplina do - sobretudo no caso ma sc ulino, no que se refere a o olhar, a o sono, à comida, à bebida, e, no feminino, à fala - não cederá à carne/vontade, alcançando a salvação juntamente com a alma. Logo, é com o corpo que se peca; é no corpo que são sofridas as conseqüências do pecado; é no corpo que se luta contra a came/vontade; é o corpo que deve ser constantemente disciplina do, sendo coloca do, muita s vezes, sob sofrimentos e doenças.

Assim, o corpo pode ser bom ou mau e, portanto, ser digno de ser defendido; ser curado; e, no caso das 
pessoas cuja santidade foi socialmente reconhecida, ser venerado. A dor e o sofrimento também são legitimados: como dádivas divinas, dentro da lógica berceana, não a dvêm necessariamente de causas naturais, mas são concedidos por Deus.

Gonzalo de Berceo apresenta uma percepção diferenciada dos corpos de Oria e Domingo. Oria é mulher e, portanto, considerada mais corporal, mais próxima da ma téria. Ela está a meio ca minho da "perfeiçã o meta física", logo, é mais fraca na disciplina do corpo e na luta contra a came/vontade. Ela necessita de tutela, deve isolar-se e direcionar a sua fala à autoridade eclesiástica masculina. Domingo, como homem, hierarquicamente está ma is próximo da perfeição. Ma is racional, está mais apto a controlar seu corpo, a combatera came e a relacionar-se com outros corpos.

Essa s concepções sobre corpo, a lma, carne/ vontade e sofrimento, enunciadas por Gonzalo de Berceo em seu poema, reforçam a autoridade do saber universitá rio e dos textos patrísticos misóg inos, a o exemplific ar, com suas biografias, como homens e mulheres estavam hierarquic amente posicionados devido aos distintos graus de perfeição. Ta mbém rea firma $m$ a disciplina corporal d ifund ida nos meios moná stic os, ta is como o jejum, o silêncio, a abstinência de vinho, mas o fazem de forma cria tiva, pois não consideram o corpo nega tivamente.

Esses textos ta mbém legitimam e explic am o poder de domínio social aspirado pela Igreja Romana: sugerem comportamentos que deveriam ser cumpridos no corpo, pois visa vam o seu disc ip lina mento; justific am o sofrimento, considerando-o como dádiva de Deus e, por extensão, abrindo caminho para que, se necessário, a Igreja lançasse mão da dor física para punir e controla r os considerados desvia ntes; a va lorizar as relíquias, rea firmam os símbolos dos cultos a os santos; reforçam, a o estimula r a luta contra a came, que cada fiel é responsável pela sua própria salvação perante Deus e a Igreja, cabendo a ele refletir sobre os seus pecados e verba lizá-os no a to da confissão.

Como clérigo, universitário, cristão e hagiógrafo, Gonzalo de Berceo foi um receptor, sistematizador e um propagador de enunciados sobre o corpo e a came no início do século XIII. Seus textos estimularam os fiéis, a exemplo de Domingo e Oria, a reproduzirem, no cotidia no, a relação hierárquica que colocava os homens como superio res à smulheres; a venera rem as relíquia s dos sa ntos; a buscarem a salvação da alma através da luta contra a came/vontade; a disciplinarem o corpo; a aceitarem os sofrimentos físicos e a confessar suas faltas. Ao enunciar tais idéias, o poeta reafirmava tanto o poder da Igreja 
Romana sobre os corpos dos fiéis, como o dos homens sobre as mulheres.

\section{Referências bibliográficas}

BíBLIA. Português. Bíblia On Line. Versã o 2.0. Tra duçã o: J oão Ferreira Almeida. São Paulo: Socieda de Bíblica do Bra sil, 1999a.

BíBLIA. Vulgata. Bíblia On Line. Versão 2.0. São Paulo: Sociedade Bíblica do Brasil, 1999b.

BíBபA DE J ERUSALÉM. São Pa ulo: Pa ulinas, 1985.

CASAGRANDE, Carla; VECCHIO, Silvana. "Pecado". In: LE GOFF, Jacques; SCHMITT, Jean-Claude. Dicionário Temático do Ocidente Medieval. São Paulo: Imprensa Oficial de São Paulo/Edusc, 2002. 2 v. v. 2, p. 337-351.

CLARK, Elizabeth A. "Women, Gender, and the Study of Christian History." Church History, v. 70, n. 3, 2001. p. 395-426.

DUBY, Georges. "Reflexões sobre o so frimento físic o na Ida de Média". In: ____. Idade Média, Idade dos homens. Sã o Paulo: Compannia das Letras, 1989. p. 161-165.

DUFFY, Eamon. Santos e pecadores: história dos Papas. São Paulo: Cosac \& Naify, 1998.

ELIAS, Norbert. O processo civilizador. Rio de J a neiro: J orge ZaharEd., 1994. 2v.

ERNESTO DELGADO, Edmundo. "Ascetas e penitentes en el discurso de los padres de la Iglesia: hacia una revisión histórica del modelo hagiográfico de la leyenda de Santa Maria Egipcíaca en la Alta Edad Media". Romance Quarterly, v. 50, n. 4, p. 281-301, 2003.

FOUCAULT, Michel. A arqueologia do saber. 3 ed. Rio de Janeiro: Forense, 1987.

GAJ ANO, So fia B. "Sa ntida de". In: LE GOFF, J a cques; SC HMITT, Jean-Claude. Dicionário Temático do Ocidente Medieval. São Paulo: Imprensa Oficial de São Paulo/ Edusc, 2002. v. 2, p. 449-463.

GARC ÍA DE LA FUENTE, O legario. El la tín bíblico y el español medieval hasta el 1300. Logroño: Instituto de Estudios Riojanos, 1992.

GAUC HER, Elisa beth; DOUFO URNET, J ean (Eds.). Revue des Sciences Humaines, n. 251, v. 3 (L'Hag iogra phie), jul./ set. 1998.

GIMENO CASALDUERO, J oaquim. "La vida de Santa Oria de Gonzalo de Berceo: nueva interpretación y nuevos datos". Annales de Literatura Española, n. 3, p. 235281, 1984.

GONZALO DE BERCEO. Obras completas. Estudo e edição crítica por Brian Dutton. Londres: Tamesis Books, 1978. 5v. v. 4: La vida de Santo Domingo de Silos. v. 5: El 
sa crificio de la Misa, La vida de Santa Oria, El martirio de San Lorenzo.

KLAPISC H-ZUBER, Christine. "Ma sc ulino/feminino". In: LE GOFF J a cques; SC HMITT, J ean-Claude. Dic ioná rio Temático do Ocidente Medieval. São Paulo: Imprensa Oficial de São Paulo/Edusc, 2002. v. 2, p. 137-150.

LAQUEUR, Thomas. Inventando o sexo: corpo e gênero dos gregos a Freud. Rio de J a neiro: Relume- Duma rá, 2001.

LE GOFF, J a cques. Por a mor às cidades. Sã o Paulo: UNESP, 1998.

LOI, Vic enzo. "Carne". In: Dicionário Patrístico e de Antigüidades C ristãs. Petróp olis: Vozes, 2002. p. 345.

MARTIN ALONSO. Diccionario Medieval Español. Desde las Glosas Emilianenses y Silenses (s. X) hasta el siglo XV. Salamanca: Universidad Pontifíc ia de Salamanca, 1986. $2 \mathrm{t}$

MONGEШ, Lênia Márcia (Coord.). Mudanças e rumos: o Ocidente Medieval (séculos XI-XIII). Cotia: Íbis, 1997.

ORLANDI, Eni Puccinelli. Discurso e texto: formulação e circulação dos sentidos. Campina s: Pontes, 2001.

PILOSU, Mário. A mulher, a luxúria e a Igreja na Ida de Média. Lisboa: Estampa, 1995.

RODRIGUES, J osé Carlos. O corpo na história. Rio de J a neiro: Fiocruz, 1999.

RUFFINATO, Aldo (Ed.). "Vida de Sa nto Domingo de Silos". In: GONZALO DE BERCEO. Obra completa. Coordenada por Isa bel Úria Maqua. Madrid: Espa sa-Calpe, 1992. p. 257453.

SALSBURY, J oyce E. The Latin Doctors of the Church on Sexuality. J ournal of Medieval History, n. 12, 1986. p. 279-289.

SARANYANA, J osep-Ignasi. La discusión medieval sobre la condición femenina (Siglos VIII al XIII). Salamanca: Universidad Pontificia de Salamanca, 1997.

SAUG NIEUX, Joël. "Vocabulário da morte na Espanha do Século XIII segundo a obra de Berceo". In: BRAET, Herman; VERBEKE, Werner (Eds.). A morte na Idade Média. São Paulo: Edusp, 1996. p. 146-180.

SC OTT, J oan W. Gender and Politc s of History. Revised Edition. New York: Columbia University Press, 1988.

SCHMITT, Jean-Claude. "Corpo e alma". In: LE GOFF, J a cques; SCHMITT, J ean-Cla ude. Dic ioná rio Temático do Ocidente Medieval. São Paulo: Imprensa Oficial de São Paulo/Edusc, 2002. v. 1, p. 254-265.

SILVA, And réia C ristina Lopes Frazão da. "Reflexões sobre a Educação Clerical na Idade Média: um estudo compa rativo". Plures Humanida des, v. 2, p. 27- 45, 2001.

SOT, Michel. "Mépris du monde et résistance des corps aux XI et XII siècles". Médiévales, n. 8, p. 6-17, 1985. 
SPIDLIK, Thomas. "Corpo". In: Dicionário Patrístico e de Antigüida des C ristãs. Petróp olis: Vozes, 2002. p. 258-259.

THOMASSET, Claude. "La naturaleza de la mujer". In: DUBY, Georges; PERROT, Michele (Dirs.). Historia de las mujeres en Occidente. Madrid: Taurus, 1992. v. 3: La Edad Media. La mujer en la familia y en la sociedad. p. 61-90.

ÚRIA MAQUA, Isabel. "Nota Introdutória Poema de Santa Oria". In: GONZALO DE BERCEO. Obra Completa. Coordenada por Isabel Úria Maqua. Madrid: EspasaCalpe, 1992. p. 494-496.

VAUC HEZ, André. A espiritualidade na Idade Média Ocidental. Séculos VIII a XIII. Rio de J a neiro: J orge Zahar, 1995.

VERGER, J a c ques. Cultura, ensino e sociedade no Ocidente nos séculos XII e XIII. Ba uru, SP: Ed usc, 2001.

VEYNE, Paul. Como se escreve a História. Foucault revoluciona a História. Brasília: UnB, 1982.

WALSH, J ohn K. "A Posible So urce for Berceo's Vida de Santa Oria." Modern Language Notes, n. 87, 1972. p. 300-307.

WEISS, Julian. "Writing, Sanctity and Gender in Berceo's Poema de Santa Oria." Hispanic Review, v. 64, Aut. 1996. p. 447-465.

[Recebido em junho de 2005 e aceito para publicação em abril de 2006]

\begin{abstract}
Body and Flesh: A Reading of Vida de Santo Domingo de Silos and Vida de Santa Oria from the Gender Category Perspective

Abstract: Based on post-structura lism's proposition, a dopted by Scott, that "meanings a re not fixed in a culture's lexic on", the present article aims to disc uss the meanings of two medieval Spanish words - cuepo and came - in hagiographic texts written by Gonzalo of Berceo in the first half of the century XIII, Vida de Santo Domingo de Silos and Vida de Santa Oria, from the gender category perspective. We want to verify as this category is articulated to Berceo's conceptions about the body and the flesh, looking for a mbiguities and conflicts.

Key Words: Middle Ages; Gender; Hagiography; Body; Flesh.
\end{abstract}

